\title{
AUTONOMIA E OPORTUNIDADES MOTIVACIONAIS DOS EXECUTIVOS DE EMPRESAS DE GRANDE PORTE
}

\author{
Matheus Bernardo dos SANTOS ${ }^{1}$ \\ Alessandra Costenaro MACIEL ${ }^{2}$ \\ Daniel Knebel BAGGIO ${ }^{3}$ \\ Bruna Faccin CAMARGO ${ }^{4}$ \\ ${ }^{1}$ Bacharel em Administração, Escola de Administração da Faculdade Meridional (IMED). \\ ${ }^{2}$ Doutoranda em Administração na Universidade de São Caetano do Sul (USCS). Coordenadora da Pós-Graduação \\ Lato Sensu (IMED). \\ ${ }^{3}$ Doutor em Contabilidade e Finanças (UNIZAR). Docente no programa de Mestrado e Doutorado em Desenvolvimento \\ (UNIJUI). \\ ${ }^{4}$ Doutoranda em Contabilidade e Finanças (UNIZAR). Docente no curso de Ciências Contábeis (FAISA)
}

Recebido em: 09/03/2016 - Aprovado em: 25/03/2017 - Disponibilizado em: 01/07/2017

\begin{abstract}
RESUMO
Este trabalho aborda o ethos do executivo de Passo Fundo e suas escolhas de emprego e a busca pela felicidade e sucesso. Tal estudo foi motivado devido ao cenário competitivo e que prima por resultados, somado ao fato de a cidade intensifica o seu desenvolvimento e observando a entrada de empresas no município. Sendo assim, o objetivo geral é identificar os fatores que levam os executivos das empresas de Passo Fundo/RS a trocar de emprego, tendo em vista como os fatores que condicionam a felicidade interferem nesse processo. Entre os fatores pesquisados foi abordado o conceito sobre a felicidade, qualidade de vida no trabalho, estresse, tempo e crise, tecnologias, mudanças, metas, objetivos pessoais e profissionais, orgulho, autonomia, relacionamento, confiança e carreira descritos de cada gestor. Para tanto, foi realizada entrevistas de profundidade com cinco gestores do município, questionando como tomariam suas decisões. Nesse prisma a pesquisa foi realizada de forma não estruturada, direta e pessoal, onde foi analisado as motivações, crenças e atitudes dos executivos quanto as escolhas de trabalho no município de Passo Fundo. Essa condição foi aceita com o intuito de responder o que é considerado mais importante e o que levaria esses executivos a saírem das empresas que trabalham. Os resultados apontam que os gestores executivos primam pela autonomia no trabalho e que o salário não é o ponto mais relevante no processo de escolha, ainda sim verificou-se que existe um desejo por esses profissionais em atuarem e residirem em uma cidade mais desenvolvida que Passo Fundo.
\end{abstract}

Palavras-chave: Executivo, troca de trabalho, felicidade.

\begin{abstract}
This work approaches the realm of the executive managers in Passo Fundo and their choices regarding employment. More specifically about change of job and the search for happiness and success. That study is justified due to a very competitive environment that requests outcomes, plus the fact that Passo Fundo/ RS is speeding up its development and is receiving more companies. In this way, this study's main goal is to identify the factors that have impact on the executive manager's job change in Passo Fundo/RS. Among the different evaluated factors are the concepts on happiness, quality of life at work, stress, time and crises, technologies at work, changes, goals, personal and professional objectives, pride, autonomy, relationship, trust and career path defined for each executive manager. Going along with that, five thorough interviews were made with five executive managers in Passo Fundo, asking about how would be their decisions when pondering the formerly mentioned concepts. The research is made in a non-structured way, direct and personal, while studying the executive managers' motivations, beliefs and attitudes towards job decisions in Passo Fundo. That condition has acceptance because it can answer on what is the most relevant matter in the jobs choices, and what would led the executive managers to leave the current company. The results show that managers' most important factor is autonomy at work. Wage, however, is not the most relevant point in the decision making process. Finally, it was found that the managers have a desire to work and to live in a more developed city than Passo Fundo.
\end{abstract}

Keywords: Executive, labor exchange, happiness. 


\section{INTRODUÇÃO}

A evolução do mundo corporativo é uma questão que intriga todos os gestores e executivos das organizações, envolvendo diversos aspectos gerenciais disponíveis para medir a realidade. Acompanhando essa evolução, muitos instrumentos do Management ficaram no passado se tornando imprecisos. Muitos estudos fazem eco às profundas mudanças impostas as empresas, como as aspirações e valores das novas pessoas que nelas trabalham (SOUZA, 2012).

Verifica-se hoje o mundo profissional como um organismo amplo e complexo, pois vive-se uma constante busca de aumento de produtividade, a crescente pressão por resultados e muitas horas extra de trabalho, e cada vez vem mais a tona a pergunta de como buscar a felicidade?

Conforme Sobrinho e Porto (2012), a felicidade aparece em uma ceara de entendimento no que tange experiências de prazer e desprazer, sendo considerada também como uma preocupação científica onde é importante saber o quanto as pessoas são felizes. Dessa forma, a literatura adotou como sinônimo de felicidade o bem-estar e compreende que este se relaciona a esferas da vida, como o trabalho. Tanure et al. (2007) colabora para o pensamento neoempresarial de Souza (2012), apontando características do mundo corporativo, cada vez mais competitivo e valorização da ascensão individual, destacando-se no âmbito social.
Dessa forma, são os colaboradores e não as organizações o próprio capital corporativo. Essa visão do capital humano se encontra com uma lógica ascendente, lógica esta que gera um funil clássico, que conforme a progressão da carreira mais difícil é a continuidade do crescimento dos indivíduos.

Ainda segundo os autores para captar de uma forma mais macro as relações entre organização e capital humano, deve-se levar em conta o que existe além de um contrato formal, empregando-se a expressão contrato psicológico. Contudo, a lealdade dos colaboradores para com as empresas vem se deteriorando, a partir de uma série de eventos, dentre os quais o downsizing, a quebra desses contratos psicológicos e a utilização de trabalhadores em contingente. Thurow (1997), compreende que o medo iminente de perder o trabalho tem sido uma das formas que as empresas utilizam para manterem seus colaboradores.

Portanto, quando citada a qualidade de vida em uma perspectiva sócio-técnica é comum encontrar uma relação direta com a felicidade, pois as organizações estão com seus modelos de gestão baseadas em pessoas e seus executivos se vêm surpresos, que mesmo depois de várias conquistas profissionais na pós-modernidade capitalista, se deparam com a insegurança na pressão exercida pelos fatores que seguem: gestão de tempo, competências que o profissional possui ou não, alinhamento entre orgulho e os 
valores da empresa, fazer o que gosta de fazer, os personagens assumidos pelos executivos na execução de seus deveres, e a sensação de dívida com a família e com a empresa (TANURE; NETO; ANDRADE, 2007).

Assim, devido à preocupação em compreender as escolhas dos executivos nas organizações, triangulando fatores que colaboram para a permanência dos mesmos nas empresas até a importância de suas escolhas, esse estudo procura identificar como o executivo trabalha a carreira, qualidade de vida e as escolhas de emprego em Passo Fundo fornecendo informações que favoreçam as mudanças organizacionais destinadas a aumentar a satisfação do trabalhador. Portanto, este estudo busca compreender sobre as escolhas dos executivos no que diz respeito a crescente pressão das empresas, quanto à obtenção de resultados com um planejamento há curto prazo e que prima pela sobrevivência. Conforme Lacombe, Heilborn (2003) em uma enquete realizada no Portal Exame com 568 executivos $68 \%$ disseram que pensam em deixar o emprego e o que procura-se saber é o que mais influencia nessa decisão tendo em vista os fatores motivacionais, o stress, o medo do fracasso e a busca pela felicidade.

Diante deste contexto, o presente estudo pretende responder a questão: Que fatores levam os executivos das empresas de Passo Fundo/RS a trocar de emprego?

\section{REFERENCIAL TEÓRICO}

\subsection{OS EXECUTIVOS:}

\section{COMPORTAMENTOS E ESTRUTURAS}

Entende-se que a administração corresponde a um trabalho em grupo para alcance de objetivos dentro de uma organização. Lacombe, Heilborn (2003) da luz ao pensamento de ênfases nos comportamentos das pessoas e suas motivações para alcançar objetivos, bem como a atuação do administrador para influenciar o comportamento. Portanto, o autor inicia seu pensamento com a reflexão sobre resultados através de pessoas, relacionando o que Goleman et al. (2009) descreve sobre ativo, sendo este aquilo capaz de transformar a matéria-prima em algo mais valioso. Portanto capital intelectual é um conhecimento que transforma matérias primas tornando-as valiosas. Logo o capital intelectual é um ativo das empresas apesar da contabilidade financeira não mensura-lo ao contrário do que ocorre no mercado organizacional.

Discorrem sobre os níveis organizacionais os autores Lacombe, Heilborn (2003) considerando que as organizações são sistemas complexos destinados a atingir objetivos diferenciados também complexos, gerando a divisão do trabalho e a especialização de atividades dos órgãos e dos participantes. Portanto, se torna possível 
distinguir diversos níveis de atuação dentro de uma organização, onde cada um pode desenvolver diferentes tarefas e possuir a sua própria racionalidade.

Lacombe; Heilborn (2003) relata alguns princípios de estrutura de organização segundo Fayol, destacando quatro princípios como indispensáveis - estabilidade do pessoal; cadeia escalar; unidade de comando e unidade de direção. De acordo com as descrições a unidade de comando se organiza em um desenho onde cada subordinado recebe ordens e presta contas somente a um superior, sendo que em níveis superiores poderá haver algum conflito entre as autoridades de linha e funcional bem como em algumas solicitações de assessorias. Temos ainda a exclusividade da representatividade e responsabilidade, que demonstra a ligação direta com as responsabilidades do indivíduo, independentes da delegação para subordinados. Por fim o princípio da definição funcional dizendo que os deveres e a responsabilidade de cada posição em uma estrutura deve ser formalizado por escrito e comunicado a todos. O chefe de cada órgão deve ter autoridade para coordenar atividades, inclusive de organizar as relações funcionais clareando cada posição na estrutura organizacional.

Dessa forma em uma estruturação organizacional é necessário entender o lugar do executivo. Para Lacombe; Heilborn (2003) as estruturas podem ser funcionais departamentalizadas por critérios funcionais e em primeiro nível, colocando a empresa como o grande centro de resultados, apurando-se lucros ou prejuízos dentro de um sistema contábil, sendo eficiente em ambientes estáveis e nas situações rotineiras.

Figura 1 - Estrutura organizacional funcional departamentalizada

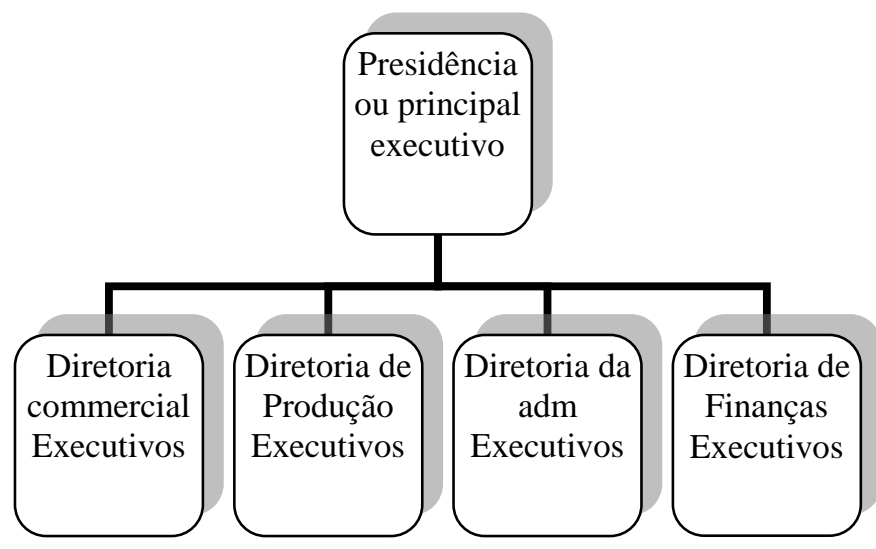

Fonte: Elaborado pelo autor, 2013

Maximiano (2004) demonstra outro modelo de estrutura através da classificação Territorial, utilizando o critério geográfico de departamentalização onde a empresa opera em uma grande área, ou em locais diferentes sendo necessária disponibilização em cada área, de um certo grau de recursos e autonomia. 
Figura 2 - Estrutura organizacional funcional geográfica

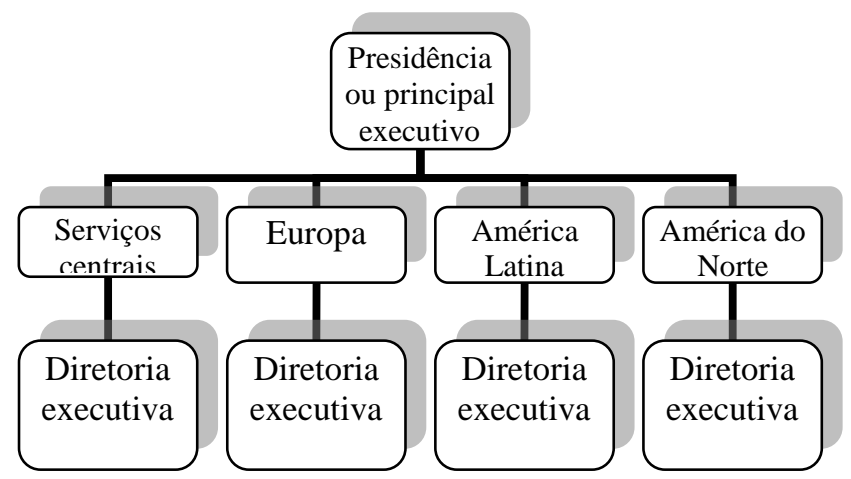

Fonte: Elaborado pelo autor, 2013.

Lacombe; Heilborn (2003) fala sobre estruturas divisionais complementando o que foi observado e descreve que a divisionalização é a maneira de separar uma organização com estrutura funcional em divisões autônomas, denominadas centros de resultados, ou unidades de negócios, baseando-se em serviços, produtos, ou ainda regiões geográficas. Organização por área de conhecimento como é o caso de institutos de pesquisa, escola e laboratórios e projetos cuja atividade é finita, ou seja, por um espaço de tempo com o objetivo de fornecer um produto ou serviço singular.

Nessa perspectiva a pesquisa é organizada em assuntos pertinentes a vida desse profissional, onde sob a influência da obra de Tanure et al. (2007) é que desbravada as prováveis causas motivacionais empregatícias da vida corporativa dos executivos de Passo Fundo em empresas de Grande porte.

\subsection{INTERESSES PESSOAIS VERSUS} INTERESSES ORGANIZACIONAIS

Para Tanure, et al. (2007) os executivos não estão satisfeitos com a quantidade de investimentos de tempo e energia na vida pessoal, incluindo parceiro amorosos, filhos e pais. Uma pesquisa realizada no início dos anos 90 revelou que já naquela época o executivo estava insatisfeito com a falta de tempo para dedicar a sua vida privada, porém até metade daquela época as estruturas organizacionais ainda eram muito verticalizadas. Divide-se, portanto as escolhas dos executivos sendo que é cada pessoa que determina a quantidade de tempo investida em cada área.

Marras (20110) fala que existem interesses obviamente desiguais, divergentes e até antagônicos em uma organização, sendo que para alguns pode ser o recebimento máximo por parte da empresa, em termo de remuneração, vantagens e benefícios, e para a empresa é fazer-se cumprir os seus objetivos.

Tanure et al. (2007) levam o pensamento ao objetivo de pesquisa, sendo que a percepção dos executivos brasileiros é de insatisfação quanto à relação de interesses pessoais e profissionais, onde $65 \%$ dizem investir mais de $70 \%$ do seu tempo e da sua energia na vida profissional; entre estes $65 \%$, $59 \%$ relatam não se sentirem bem investindo nessa área da vida e apenas $22 \%$ dizem satisfeitos e quando questionados os 
conjugues as resposta se amenizam, mas ainda são expressivas.

Um fator importante observado por Tanure et al. (2007) é que o executivo brasileiro trabalha mais horas que o executivo de países desenvolvidos. Essa informação é obtida através da comparação entre os executivos brasileiros e seus pares em empresas internacionalizadas. Informação ressaltada pelo espanto por parte dos executivos americanos e europeus quanto ao excesso de trabalho no Brasil. É interessante ressaltar ainda um aspecto cultural no perfil do executivo brasileiro. Em uma entrevista realizada pelos autores Tanure et al.(2007) com um executivo americano é exposto um lado coletivista e emocional do país e com o foco nas relações pessoais, "nos Estados Unidos fazemos negócios, e depois, se possível, fazemos amigos. No Brasil fazemos amigos, se possível, fazemos negócios".

\subsection{CARREIRA E QUALIDADE DE} VIDA

Com um mercado cada vez mais dinâmico e competitivo os executivos brasileiros e de uma forma geral se veem no meio das adaptações, onde de acordo com Bohlander et al. (2003) as organizações estão mudando suas regras básicas de gestão de pessoas, com cargos mais flexíveis tornando os processos de mudanças mais fáceis. Isso se da devido à preocupação que as organizações estão tendo na concepção de trabalho, adotando assim estruturas que considerem as aspirações de seus executivos e seus devidos interesses.

Nessa linha de pensamento Hall (2002) considera diferentes modalidades de carreiras em sua definição, atribuindo-as ao próprio termo: carreira como habilidade vertical, independente da área, profissão ou organização, tais como: médico, advogado e professor. Carreiras como sequência de empregos durante a vida, que parte da ideia de que todos trabalhadores têm carreira independente de uma direção, up/down. Carreira como sequencia de experiências relacionadas a funções ao longo da vida, em diferentes segmentos. Para Boog (2003) a carreira executiva liga-se de uma forma ampla em um somatório de encontros, emoções, ações e omissões ao longo da vida, e é este composto que forma o que somos.

Verifica-se, portanto através de Bohlander (2003) que as empresas e os indivíduos compartilham o desejo de desenvolver e explorar ao máximo seus conhecimentos, esse desejo segundo Boog (2003) é um dos aspectos ligados às leis que regem a vida conforme estudos do pensador Rudolf Steiner (1861-1925). Existe assim uma dependência direta da realização profissional com a qualidade de vida tendo em vista o conceito das leis Biográficas baseando-se no amadurecimento de mais de um fator específico conforme Boog (2003). 
Pesquisas no meio mediático apontam que os colaboradores estão menos satisfeitos a cada ano, independente da melhora de processos de RH nas companhias. De acordo com Krznaric (2012) a partir do momento que a renda é suficiente para sanar as necessidades básicas , os ganhos monetários acrescentam pouco sobre a satisfação dos funcionários de uma empresa.

Um questionamento interessante proposto por Krznaric (2012) é que os fatores que conduziam o "sentido de vida" migraram de outros sentidos sociais. Associa-se a seguinte explicação: quando as pessoas não tinham como escolher a profissão, o encontro de sentido para a carreira profissional acontecia em outros meios, como a religião e a vida em comunidade.

Logo uma nova abordagem aparece nessa ceara. Se as pessoas possuem mais opções de trabalho, por que estão mais angustiadas? Schwartz (2007) explica tal fenômeno através do paradoxo da escolha, onde quanto mais diversidade de escolhas profissionais, pessoais e materiais, mais alternativas para lidar, mais incidência de equívocos, e mais esgotamento da psique humana. Para Schwartz (2007) as expectativas de sucesso crescem na mesma proporção que aumentam as escolhas. Dessa forma o individuo deve compreender que invariavelmente algumas escolhas devem ficar de lado, pois o excesso de escolhas podem gerar experienciais menos gratificantes (HAYNES, 2009).

\subsection{SUCESSO E FELICIDADE}

A busca pela felicidade é um dos principais assuntos que permeiam os estudos da administração no campo dos recursos humanos, conforme (FIORELLI, 2006). Sabese que é comum a busca por sucesso e felicidade para todos os indivíduos e que de acordo com Myers (1999) pessoas felizes projetam cenários positivos tanto no sentido pessoal quanto a atuação em equipes. Para Fiorelli (2006) as organizações buscam compreender todos os aspectos que conduzem a competitividade e deixam de lado a compreensão real de felicidade.

No entanto Zanelli et al. (2004) relatam a ação de outras emoções no trabalho, dividindo em quatro funções básicas as emoções e afetos: a sobrevivência da espécie, construção histórica, aprendizagem e ajustamento social e a expressão da subjetividade e da individualidade. Ainda Zanelli et al. (2004) ressaltam uma discussão sobre o domínio da cognição sobre a emoção, onde a cognição aparece como uma atividade racional, intelectual e consciente ligada aos três processos mentais básicos: pensamento (cognitivo) sensação (emocional) e vontade (conativo) conectando-se a uma visão da mente cuja a natureza é imaterial, distinta do 
corpo como uma concepção cartesiana de mente

Dessa forma para que seja possível a análise do binômio Sucesso e Felicidade é importante que seja compreendida que o resultado de sucesso nem sempre é a felicidade e que a mesma é uma emoção complexa onde despertá-la é muito mais fácil do que mantê-la conforme Fiorelli (2006). Ainda sobre a posse, Lacombe, Heilborn (2003) identifica a felicidade como resultado de um processo civilizatório, ou seja, benefícios da civilização que sejam tangíveis e passíveis de mensuração, como indicadores biomédicos, sociais e econômicos. Nesse prisma Tanure et al. (2007) chamam a atenção para algumas características pessoais e individuais que influenciam diretamente a ideia de sucesso e felicidade, como: sexo, idade, gênero, cargo e perfil psicológico.

\section{MÉTODO}

A investigação do fenômeno a ser compreendido será realizada por meio de uma pesquisa qualitativa de natureza exploratória, buscando na situação de emprego os critérios e os motivos que levam os executivos das empresas de Passo Fundo escolherem a organização que trabalham, tendo em vista uma gama de fatores que compreendem essa decisão.

A pesquisa é obtida também como de levantamento (survey), pois realizou a obtenção de dados que se referem a características dos executivos de Passo Fundo, além de verificar ações e opiniões desse público alvo.

Isto posto, este trabalho utiliza do modelo de entrevistas analíticas individuais que sondam o detalhe do pensamento dos executivos de Passo Fundo, provendo assim percepções e compreensão para o estudo. Dessa forma foram realizadas entrevistas individuais (Apêndice A), com os executivos de Passo Fundo respeitando o tempo máximo de $1 \mathrm{~h} 30 \mathrm{~m}$ em um esquema pré-determinado, contudo sem ser estruturado.

Tendo em vista a necessidade de entendimento do perfil dos executivos no município de Passo Fundo, a pesquisa foi aplicada em uma amostra. Por isso, na definição da população alvo foram selecionados executivos a nível tático ou estratégico das organizações de Passo Fundo no estado do Rio Grande do Sul, sem idade e sexos definidos, em situação de emprego e em diferentes setores e organizações. Sendo assim, foram entrevistados cinco executivos das empresas: Manitowoc, BSBios, Kuhn, Grupo RBS, Vivo S/A.

\section{RESULTADOS}

A análise de resultados é organizada em seções específicas de acordo com o roteiro de entrevista, coordenada através dos temas: felicidade, qualidade de vida no trabalho, 
estresse, tempo e crise, tecnologias no

\begin{tabular}{|c|c|c|c|c|}
\hline & & $\begin{array}{c}\text { sem } \\
\text { ana } \\
\text { l }\end{array}$ & & de \\
\hline A & $\begin{array}{l}3 \\
4\end{array}$ & $44 \mathrm{~h}$ & Indústria & Sim \\
\hline B & $\begin{array}{l}4 \\
0\end{array}$ & $75 \mathrm{~h}$ & $\begin{array}{l}\text { Comunic } \\
\text { ação }\end{array}$ & Sim \\
\hline $\mathrm{C}$ & 4 & $\begin{array}{l}44 \mathrm{~h} \\
\text { à } \\
50 \mathrm{~h}\end{array}$ & Indústria & Sim \\
\hline $\mathrm{D}$ & 7 & $\begin{array}{c}55 \mathrm{~h} \\
\text { à } \\
60 \mathrm{~h}\end{array}$ & Indústria & Sim \\
\hline $\mathrm{E}$ & 3 & $50 \mathrm{~h}$ & $\begin{array}{l}\text { Telecom } \\
\text { unicação }\end{array}$ & Sim \\
\hline
\end{tabular}

Fonte: Elaborado pelo autor, 2013.

01 de uma cidade de porte menor e 04 gestores de cidades de porte maior que Passo Fundo.

De uma forma geral todos os gestores trabalham mais que as horas contratadas e já trabalharam em outras empresas. Além disso, trabalharam em segmentos diferentes do que atualmente atuam. Conforme demonstrado na Tabela 2.

Tabela 1 - Segmentação dos entrevistados

\begin{tabular}{ccccc}
\hline & & Ho & & Trab \\
Ge & Id & ras & & alho \\
sto & a & de & Segment & u em \\
r & d & tra & o que & outr \\
& e & bal & atua & a \\
& & ho & & cida \\
\hline
\end{tabular}

Tabela 2 - resumo das respostas dos entrevistados

\begin{tabular}{ccc}
\hline $\begin{array}{c}\text { Assunto } \\
\text { Pesquisado }\end{array}$ & Gestor & \multicolumn{1}{c}{ Respostas } \\
\hline & A & $\begin{array}{l}\text { Se sente feliz, sinônimo } \\
\text { de felicidade é autonomia. }\end{array}$ \\
\cline { 2 - 3 } $\begin{array}{c}\text { Felicidade no } \\
\text { trabalho }\end{array}$ & B & $\begin{array}{l}\text { Se sente feliz, condiciona } \\
\text { a felicidade à autonomia. }\end{array}$ \\
\cline { 2 - 3 } & C & $\begin{array}{l}\text { Se sente feliz, devido à } \\
\text { afinidade pelo que faz. }\end{array}$ \\
\cline { 2 - 3 } & D & Se sente feliz, justifica \\
\hline
\end{tabular}




\begin{tabular}{|c|c|c|}
\hline & & com o reconhecimento. \\
\hline & $\mathrm{E}$ & $\begin{array}{l}\text { Se sente feliz, sinônimo } \\
\text { de felicidade é autonomia. }\end{array}$ \\
\hline \multirow{5}{*}{$\begin{array}{l}\text { Aquisição de bens } \\
\text { materiais }\end{array}$} & $\mathrm{A}$ & $\begin{array}{l}\text { Sinônimo de felicidade, } \\
\text { fator motivacional. }\end{array}$ \\
\hline & $\mathrm{B}$ & $\begin{array}{l}\text { Não é um fator } \\
\text { motivacional. }\end{array}$ \\
\hline & $\mathrm{C}$ & $\begin{array}{l}\text { É um fator motivacional e } \\
\text { relaciona com a ambição. }\end{array}$ \\
\hline & $\mathrm{D}$ & $\begin{array}{l}\text { Considera consequências } \\
\text { do trabalho. }\end{array}$ \\
\hline & $\mathrm{E}$ & $\begin{array}{l}\text { Diz-se tranquilo, não é um } \\
\text { fator importante. }\end{array}$ \\
\hline \multirow{5}{*}{$\begin{array}{l}\text { Qualidade de vida } \\
\text { no trabalho }\end{array}$} & $\mathrm{A}$ & Flexibilidade de horários. \\
\hline & $\mathrm{B}$ & $\begin{array}{l}\text { É dar propósito a sua } \\
\text { equipe }\end{array}$ \\
\hline & $\mathrm{C}$ & $\begin{array}{l}\text { Harmonia no ambiente de } \\
\text { trabalho, horários } \\
\text { flexíveis. }\end{array}$ \\
\hline & $\mathrm{D}$ & $\begin{array}{l}\text { Separar os momentos, } \\
\text { trabalho e lazer. }\end{array}$ \\
\hline & $\mathrm{E}$ & $\begin{array}{l}\text { É ter foco no trabalho, sem } \\
\text { sobrecarga. }\end{array}$ \\
\hline
\end{tabular}

\begin{tabular}{|c|c|}
\hline $\mathrm{A}$ & $\begin{array}{l}\text { Se sente estressado, } \\
\text { sobrecarga de trabalho e } \\
\text { metas. }\end{array}$ \\
\hline B & $\begin{array}{l}\text { Naturalmente estressado, o } \\
\text { estresse é uma energia boa, } \\
\text { é motivador. }\end{array}$ \\
\hline $\mathrm{C}$ & $\begin{array}{l}\text { Se sente estressado, devido } \\
\text { à rotina. }\end{array}$ \\
\hline $\mathrm{D}$ & $\begin{array}{l}\text { Se sente estressado e é uma } \\
\text { fonte de motivação. }\end{array}$ \\
\hline $\mathrm{E}$ & $\begin{array}{l}\text { Se sente constantemente } \\
\text { estressado e considera o } \\
\text { estresse normal. }\end{array}$ \\
\hline
\end{tabular}

\begin{tabular}{|c|c|c|}
\hline \multirow{5}{*}{$\begin{array}{l}\text { Crises na } \\
\text { empresa }\end{array}$} & $\mathrm{A}$ & $\begin{array}{l}\text { São negativas, já pediu } \\
\text { demissão quando passou } \\
\text { por uma crise. }\end{array}$ \\
\hline & B & É intrínseco, e não o afeta. \\
\hline & $\mathrm{C}$ & Crises geram desconfiança. \\
\hline & $\mathrm{D}$ & $\begin{array}{l}\text { Liga crises ao fato de não } \\
\text { ser reconhecido, já pediu } \\
\text { demissão quando passou } \\
\text { por uma crise. }\end{array}$ \\
\hline & $\mathrm{E}$ & $\begin{array}{l}\text { Crise gera trabalho em } \\
\text { dobro, sobrecarga. }\end{array}$ \\
\hline \multirow{5}{*}{$\begin{array}{l}\text { Utilização de } \\
\text { tecnologias }\end{array}$} & A & $\begin{array}{l}\text { Adianta o trabalho, acessa } \\
\text { remotamente em casa. }\end{array}$ \\
\hline & B & $\begin{array}{l}\text { Adianta o trabalho, acessa } \\
\text { remotamente em casa. }\end{array}$ \\
\hline & $\mathrm{C}$ & Utiliza para checar e-mails \\
\hline & $\mathrm{D}$ & $\begin{array}{l}\text { Consideram } \\
\text { indispensáveis }\end{array}$ \\
\hline & $\mathrm{E}$ & $\begin{array}{l}\text { Consideram } \\
\text { indispensáveis }\end{array}$ \\
\hline \multirow{5}{*}{ Mudanças } & $\mathrm{A}$ & $\begin{array}{l}\text { É costumado a mudanças } \\
\text { prefere cenários de } \\
\text { instabilidade, não } \\
\text { trabalharia em empresas que } \\
\text { não mudam. }\end{array}$ \\
\hline & $\mathrm{B}$ & $\begin{array}{l}\text { Possibilitam o } \\
\text { desenvolvimento, não afeta } \\
\text { suas escolhas de trabalho. }\end{array}$ \\
\hline & $\mathrm{C}$ & $\begin{array}{l}\text { Considera momentos de } \\
\text { desafios e escolhe empresas } \\
\text { que tenham a mudanças } \\
\text { constantes. }\end{array}$ \\
\hline & $\mathrm{D}$ & $\begin{array}{l}\text { São necessárias e que isso } \\
\text { não afeta suas escolhas de } \\
\text { trabalho. }\end{array}$ \\
\hline & $\mathrm{E}$ & $\begin{array}{l}\text { O desestabiliza e gera } \\
\text { estresse e aumento de } \\
\text { trabalho. }\end{array}$ \\
\hline
\end{tabular}




\begin{tabular}{|c|c|c|}
\hline \multirow{5}{*}{ Metas } & A & $\begin{array}{l}\text { Não desmotivam deve ter } \\
\text { planejamento e fazer sentido. }\end{array}$ \\
\hline & B & $\begin{array}{l}\text { Estabiliza o ambiente, vê } \\
\text { som elas possibilidade de } \\
\text { crescimento. }\end{array}$ \\
\hline & $\mathrm{C}$ & $\begin{array}{l}\text { Sentimentos de dívida } \\
\text { quando não entrega as metas } \\
\text { da empresa. }\end{array}$ \\
\hline & $\mathrm{D}$ & $\begin{array}{l}\text { Possui muitas metas e faz } \\
\text { Coaching como apoio na } \\
\text { condução das mesmas. }\end{array}$ \\
\hline & $\mathrm{E}$ & $\begin{array}{l}\text { Geram às vezes } \\
\text { questionamentos se } \\
\text { realmente possui } \\
\text { competências para sua } \\
\text { função. }\end{array}$ \\
\hline
\end{tabular}

A Está com os objetivos

alinhados com o da

empresa, pretende morar

em Passo Fundo.

\begin{tabular}{ll}
\hline B & Está com seus objetivos \\
& alinhados com o da \\
& empresa e isso é \\
& importante para a escolha \\
& do trabalho.
\end{tabular}
C Não sabe se seus
Objetivos objetivos estão de acordo, corporativos $\mathrm{X} \quad$ justifica dizendo que esta
objetivos pessoais aproveitando um momento de expansão da empresa.

\begin{tabular}{ll}
\hline D & Está com seus objetivos \\
& alinhados e hoje pretende \\
& atuar fora do país \\
& representando sua \\
& organização. \\
\hline E & Está com os seus \\
& objetivos alinhados, mas \\
& não em sua totalidade e
\end{tabular}

está olhando para o

mercado de trabalho.

\begin{tabular}{|c|c|c|}
\hline \multirow{5}{*}{$\begin{array}{l}\text { Ter orgulho da } \\
\text { empresa }\end{array}$} & $\mathrm{A}$ & $\begin{array}{l}\text { Não afetas suas escolhas de } \\
\text { trabalho, e não julga } \\
\text { importante. }\end{array}$ \\
\hline & B & $\begin{array}{l}\text { Acha fundamental, pois não } \\
\text { teria resultados sem isso. }\end{array}$ \\
\hline & $\mathrm{C}$ & $\begin{array}{l}\text { Possui muito orgulho da } \\
\text { empresa e jamais } \\
\text { trabalharia aonde não } \\
\text { tivesse. }\end{array}$ \\
\hline & $\mathrm{D}$ & $\begin{array}{l}\text { Possui orgulho da empresa } \\
\text { e principalmente por ser } \\
\text { uma empresa jovem. }\end{array}$ \\
\hline & $\mathrm{E}$ & $\begin{array}{l}\text { Possui orgulho de trabalhar } \\
\text { no segmento e não na } \\
\text { empresa, pois isso é } \\
\text { indiferente. }\end{array}$ \\
\hline
\end{tabular}

A Relacionamentos difíceis são desafios e não influenciam na escolha de trabalho.

B Sempre trabalhou em empresas com atrito e não influencia a sua decisão de emprego.

C Fala sobre transparência e se soubesse que uma

Relacionamentos e confiança empresa possui um superior "difícil” não aceitaria nenhuma proposta.

D Fala que deve-se entender as pessoas e que isso não afeta suas decisões de trabalho.

E Sempre vai existir problemas de relacionamento na 
empresa e que caso isso

for com um superior é

possível uma troca de

emprego.

\begin{tabular}{|c|c|c|}
\hline \multirow{5}{*}{ Idade } & A & $\begin{array}{l}\text { Não é importante, fala sobre } \\
\text { o sexo, que a mulher é } \\
\text { reprimida. }\end{array}$ \\
\hline & B & $\begin{array}{l}\text { Não é importante e também } \\
\text { não é uma medida de } \\
\text { competência. }\end{array}$ \\
\hline & $\mathrm{C}$ & $\begin{array}{l}\text { Interfere na escolha de } \\
\text { trabalho e já passou por } \\
\text { momentos complicados. }\end{array}$ \\
\hline & $\mathrm{D}$ & $\begin{array}{l}\text { Não interfere na escolha de } \\
\text { trabalho }\end{array}$ \\
\hline & $E$ & $\begin{array}{l}\text { Fala sobre integração com } \\
\text { gestores seniores e que é } \\
\text { inevitável, sendo importante } \\
\text { na escolha de trabalho. }\end{array}$ \\
\hline \multirow{5}{*}{$\begin{array}{c}\text { Promoção e } \\
\text { Família }\end{array}$} & A & $\begin{array}{l}\text { Viveria longe da família se } \\
\text { tivesse um ganho mais de } \\
100 \% \text {. }\end{array}$ \\
\hline & B & $\begin{array}{l}\text { Não viveria longe da } \\
\text { Família. }\end{array}$ \\
\hline & $\mathrm{C}$ & $\begin{array}{l}\text { Não viveria longe da } \\
\text { Família. }\end{array}$ \\
\hline & $\mathrm{D}$ & $\begin{array}{l}\text { Adaptar-se-ia } \\
\text { tranquilamente e aceitaria } \\
\text { propostas. }\end{array}$ \\
\hline & $E$ & $\begin{array}{l}\text { Aceitaria se fosse para uma } \\
\text { cidade maior que Passo } \\
\text { Fundo. }\end{array}$ \\
\hline
\end{tabular}

\begin{tabular}{ccl}
\hline O que considera & A & $\begin{array}{l}\text { Autonomia, posição } \\
\text { mais importante }\end{array}$ \\
na escolha de uma & & $\begin{array}{l}\text { ccupada, acesso a diretoria, } \\
\text { crescimento profissional e }\end{array}$ \\
empresa para se & & por último salário. \\
trabalhar? & B & O sonho a ser perseguido, \\
\cline { 2 - 3 }
\end{tabular}

\begin{tabular}{|c|c|c|}
\hline & & $\begin{array}{l}\text { se empresa ao auxilia a } \\
\text { realizar seus sonhos. }\end{array}$ \\
\hline & $\mathrm{C}$ & $\begin{array}{l}\text { Modelo de gestão, } \\
\text { autonomia, e mercado que } \\
\text { a empresa atua. }\end{array}$ \\
\hline & $\mathrm{D}$ & $\begin{array}{l}\text { Tamanho da empresa, } \\
\text { responsabilidade social e } \\
\text { desafios que ela } \\
\text { proporciona. }\end{array}$ \\
\hline & $E$ & Ascenção, promoção. \\
\hline \multirow{5}{*}{$\begin{array}{l}\text { O que o faria } \\
\text { trocar de } \\
\text { emprego, hoje? }\end{array}$} & $\mathrm{A}$ & $\begin{array}{l}\text { Autonomia e } \\
\text { reconhecimento pelo que } \\
\text { faz. }\end{array}$ \\
\hline & $\mathrm{B}$ & $\begin{array}{l}\text { Subjetivo, se empresa } \\
\text { auxilia o gestor e realizar } \\
\text { sonhos, considera } \\
\text { importante a remuneração. }\end{array}$ \\
\hline & $\mathrm{C}$ & $\begin{array}{l}\text { Oportunidade me uma } \\
\text { cidade maior que Passo } \\
\text { Fundo. }\end{array}$ \\
\hline & $\mathrm{D}$ & $\begin{array}{l}\text { Um cargo maior e posição } \\
\text { em uma cidade maior e } \\
\text { melhor que Passo Fundo. }\end{array}$ \\
\hline & $\mathrm{E}$ & $\begin{array}{l}\text { Promoção, como poderia } \\
\text { contribuir com ela e ser um } \\
\text { CEO. }\end{array}$ \\
\hline
\end{tabular}

Fonte: Elaborado pelo autor, 2013.

Já é reconhecido que fatores estressantes estão ligados à velocidade das transformações, sejam elas econômicas sociais ou culturais, e afetam todos os profissionais dos mais diferentes setores, e principalmente, os que se encontram hoje na direção das organizações. Quando realizada a entrevista com os profissionais de Passo Fundo/RS constatou-se que os mesmos 
julgam-se altamente estressados. Esse fato é interessante, considerando que o Brasil é um dos países com maior índice de estresse gerencial e possui um grande número de gestores na categoria de risco de saúde, os entrevistados consideram que atualmente eles são ou estão inseparáveis.

Ou seja, o estresse é intrínseco a rotina dos gestores de Passo Fundo. Portanto no quesito estresse, os gestores falam da sobrecarga de trabalho, e que em alguns momentos esse estresse pode ser positivo, e que estresse e suas funções são irmãos siameses, consideram que em alguns momentos possam passar por períodos mais estáveis mais que o estresse volta quando passam por turbulências. Ainda sim todos ressaltam que o estresse causa somatizações, como por exemplo, mudanças repentinas da pressão sanguínea indo até diagnósticos de conjuntivites.

No que diz respeito à felicidade os gestores entrevistados se sentem, de uma maneira geral felizes no que fazem. Justificam essa felicidade através da autonomia que possuem e pelo reconhecimento no trabalho. Salientam que a empresa deve proporcionar um sentido para a vida e que isso é um incremento importante para felicidade. Outro ponto analisado foi que os gestores julgam que os bens materiais conquistados são motivadores para seu desenvolvimento, mas o acesso a esses bens não é sinônimo de felicidade. Grande parte dos entrevistados não conquistaram tudo àquilo que desejam, mas nesse ponto ter acesso aos bens não muda seus posicionamentos quanto à escolha da empresa para se trabalhar.

Apesar das respostas sobre qualidade de vida divergirem, os gestores linkam esse constructo ao fato de desempenharem com qualidade suas funções, colocando em evidencia a preocupação com os resultados, sejam eles na gestão de tempo, no gerenciamento de outras pessoas e no desenvolvimento da empresa. Além disso, a família aparece como coadjuvante desse prisma, onde para obterem qualidade de vida no trabalho, devem estar tranquilos quanto ao bem estar de suas próprias famílias.

Quanto a crises, os gestores distinguem em seus depoimentos que as empresas em algum momento enfrentam problemas, e que isso é um fato incontrolável podendo afetar a troca de empresa, descrevem que esse fato acarreta na sobre carga de trabalho e gera dúvidas, ocasionando sentimentos de despertencimento a organização e que isso pode colocar em cheque os planejamentos pessoais e profissionais. Entre as crises que mais afetam os gestores, a que mais foi citada, foi à crise da própria empresa, a exemplo disso destacam-se as crises de cunho financeiro. Não obstante as crises pessoais não apareceram nesse contexto, ou seja apesar de instigados, crises como a perda de um familiar, que é a crise mais significativa para 
o executivo brasileiro, não afeta o julgamento do entrevistado.

Os gestores falam também que utilizam as tecnologias oferecidas pelas empresas para adiantar o trabalho e que a ausência dessa tecnologia é considerado ser um fator negativo, pois pode isolar $\mathrm{o}$ profissional, atrasar seus objetivos ou ainda gerar danos profissionais pela falta de acesso à rápida informação. Logo verificou-se que essas tecnologias não reduzem a jornada de trabalho, pelo contrário invadem outros espaços da vida privada. Dessa forma há menos limites entre o espaço pessoal, de trabalho e espaço social, ocasionando a falta de tempo.

O profissional brasileiro está acostumado a mudanças, e isso não é diferente em Passo Fundo, os gestores entrevistados falam que a mudança corporativa incentiva o desenvolvimento organizacional e que fortes mudanças não afetam as suas escolhas de emprego. Ainda sim relatam que preferem estar expostos a contínuas mudanças, de forma que esse fator pode ser compreendido com o fato de a mudança ser algo positivo no contexto brasileiro. Porquanto consideram que as mudanças afetam suas rotinas, mas não a ponto de deixarem suas posições.

$\mathrm{Na}$ ideia de metas os gestores do município, apesar de concordarem que as mesmas sejam excessivamente desafiadoras, a consideram estimulantes. Falam que o nível alto de cobrança não influencia as suas escolhas, mas que sentem insatisfeitos com a intensidade. Esse sentimento não é a ponto de se sentirem impotentes, mas paradoxalmente as cobranças acabam se traduzindo em estímulo. Existe um sentimento de dívida com a empresa quando as metas não são alcançadas, mas de uma forma geral quando os resultados ficam dentro do esperado, o sentimento de dívida desaparece.

$\mathrm{Na}$ ceara dos objetivos os gestores entrevistados entendem que é primordial estarem com seus objetivos pessoais alinhados com os da empresa, isso para que possam contribuir com mais qualidade para organização. Ainda salientam que quando há uma disparidade nesse binômio (objetivo pessoal e objetivos da empresa) podem até pedir demissão. Logo é importante para os gestores conhecerem seus objetivos e principalmente os objetivos da empresa para escolherem qual empresa trabalhar.

De uma forma geral os gestores entrevistados sentem orgulho da empresa que trabalham e orgulho em pertencer a uma empresa respeitada pela sociedade. Para os entrevistados o orgulho é considerado uma fonte de prazer e fundamental para o exercício colaborativo. Por isso o orgulho gera importância ao trabalho dos executivos de Passo Fundo significando que participam de algo "grande", compartilhando valor e gerando confiança na empresa. 
Uma das características dos gestores de Passo Fundo que surpreendeu nos resultados foi verificar que de uma forma geral os mesmos não são afetados por relacionamentos difíceis dentro das suas empresas. Contradizendo o que a fundamentação teórica explicita, ou seja, mesmo havendo atrito com chefes ou superiores, não mudam suas escolhas, preferem trabalhar ou continuar trabalhando na organização.

No que tange a idade os executivos entrevistados falam que isso não interfere nas suas escolhas, e que apesar de passarem por momentos de provações consideram inevitável o encontro de gerações. No entanto nas entrevistas aparece um fator relevante, o mundo corporativo ainda é em sua essência mais masculino e a mulher ainda sofre preconceitos. Sublinarmente verificou-se que a mulher deve se comportar como homem para ter sucesso na empresa. Portanto para a mulher atingir o topo da carreira, é preciso que ela adote um "estilo" masculino de gestão, vindo ao oposto do que as teorias modernas falam, onde o modelo de gestão feminina é melhor concebida.

Dentro da pesquisa verificou-se ainda que os executivos de Passo Fundo podem conviver longe de suas famílias, caso recebessem uma promoção com ganhos monetários maiores do que possuem. Nessa esfera entende-se que isso é influenciado diretamente pela idade, ou seja, os gestores entrevistados ainda não constituíram em sua totalidade patrimônio pessoal ou criaram filhos e conquistaram uma tranquilidade financeira. Por isso não refletem muito sobre um provável desiquilíbrio nas dimensões profissional e pessoal.

De uma maneira geral foi constatado que existe uma distorção entre as dimensões da vida profissional e pessoal e que o executivo de Passo Fundo passa por momentos de sofrimento, de maneira que existe um desafio cotidiano em equilibrar sucesso e felicidade, sendo um processo é complexo e cotidiano. A pesquisa ainda demostra que o executivo possui uma incrível capacidade de gerar resultados na sua vida profissional enquanto que a sua vida pessoal é deixada de lado.

Em relação ao que os executivos consideram mais importante na escolha da empresa para se trabalhar a pesquisa demostra que a autonomia é um fator relevante no processo de escolha da empresa, onde conforme Costa et al.(2013) essa dimensão de tarefa é capaz de levar os entrevistados a experimentarem uma significância de satisfação no trabalho. Ainda seguido da autonomia, a carreira e o tamanho da empresa aparecem também como fatores importantes na escolha da empresa para se trabalhar.

Outro fator importante é que a partir desse trabalho foi possível conhecer o que faria o executivo de Passo Fundo trocar de emprego, de forma que autonomia aparece 
como protagonista das entrevistas da mesma forma que subjetivamente a realização de sonhos, o desejo por posições melhores e a vontade de morar em uma cidade mais desenvolvida que Passo Fundo. Além disso, a remuneração não é o principal motivador para a troca de emprego.

\section{CONCLUSÕES}

Com o crescente número de empresas em Passo Fundo/RS e a vinda de novos profissionais para região, tornou-se relevante compreender o que influencia os executivos dessas empresas na hora de escolher uma organização para trabalhar, relacionando aos fatores felicidade, carreira, objetivos pessoais, estresse, idade, mudanças, metas, orgulhos, família e carreira. O estudo acabou abrindo margem para o início da compreensão sobre o ethos desses profissionais em Passo Fundo/RS, tendo em vista que o é observado em outras regiões do país também ocorre na região norte do Rio Grande do Sul.

A pesquisa foi concebida primeiramente em dois estágios, exploratória e descritiva, no entanto quando aplicado o pré-teste, verificou-se que essa alternativa deveria ser repensada, em primeiro momento devido à falta de acesso aos gestores das empresas foco, e em segundo momento pelo tempo que a pesquisa exigia. Por conseguinte foi aplicada a etapa exploratória, de levantamento (survey) para compreensão do público alvo, sendo organizadas junto a empresas de passo Fundo entrevistas de profundidade com cinco gestores de nível tático e estratégico. As entrevistas tiveram um tempo médio de 60 minutos, aplicadas dentro das companhias e sendo orientadas por um roteiro de entrevista (apêndice A). Cabe salientar que todas as entrevistas foram gravadas para posterior transcrição. Os resultados que seguem são frutos da análise dessas entrevistas suportadas pela base teórica do estudo.

Dessa forma foi possível observar que em resposta ao objetivo principal da pesquisa o executivo de Passo Fundo considera mais importante na escolha da empresa para se trabalhar a autonomia que possui na organização e a concepção de um sentido para aquilo que faz ou para o papel que vai desempenhar na empresa. No que se refere ao que mais valoriza na hora de escolher uma empresa, sendo este o objetivo (a) do estudo, o executivo identifica, em ordem de importância, a autonomia oferecida pela organização, o reconhecimento pelo que faz, o tamanho da companhia e como a empresa pode contribuir para a sua realização pessoal, incluindo também como a organização pode propiciar a ascensão para olimpo empresarial, ou seja, a presidência.

Em resposta ao objetivo (b) sobre o que os executivos entendem por "qualidade de vida" e "felicidade" o estudo trouxe a tona assuntos pertinentes a tempo e trabalho, como 
a flexibilidade de horários e a harmonia entre vida pessoal e vida profissional. Entretanto na hipotenusa da discussão a autonomia ainda prelevasse como principal sinônimo de felicidade e qualidade de vida, e em seus catetos perambulam assuntos como a sobrecarga de trabalho, onde os gestores entrevistados consideram que, quando o trabalho exige horas excessivas de dedicação não é possível ter qualidade de vida e logo essa condição acarreta na infelicidade.

Ao verificar as escolhas dos executivos quanto à carreira, sendo este $\mathrm{o}$ último objetivo da pesquisa (objetivo c), o estudo diagnosticou o seguinte cenário: os executivos de Passo Fundo almejam residir em uma cidade mais desenvolvida que Passo Fundo, ou seja, em uma cidade que lhe deem mais acesso a educação, entretenimento, e saúde. Depois que alcançam os maiores níveis de gestão que as organizações de Passo Fundo oferecem, depositam suas expectativas em atuarem fora da cidade.

Cabe salientar que em detrimentos dos agendamentos das entrevistas, houve dificuldade de contato com os entrevistados, onde por motivos de sigilo as organizações de Passo Fundo optaram em grande parte em não conceder acesso aos seus gestores. Foram contatadas 15 empresas de diferentes segmentos e somente 5 empresas concordaram em conceder a entrevista. Outro motivo que dificultou as entrevistas foi o grande número de informações que os entrevistados apresentaram, e que precisaram ser filtradas, tão logo o tempo que cada entrevista exigia acabava por dificultar o andamento do estudo.

Portanto, este estudo contém algumas limitações, pois, foi aplicado em um pequeno número de empresas e com gestores com idades semelhantes, fazendo com que não se possa generalizar os resultados para todas as organizações de Passo Fundo. Sugere-se, no entanto, que sejam realizadas outras pesquisas, inclusive quantitativas, utilizando um maior número de gestores, para que possa comparar se essas variáveis estão presentes de forma genérica na maior parte das organizações e se de fato esse é o perfil dominante dos executivos empregados em Passo Fundo/RS.

\section{REFERÊNCIAS}

BOHLANDER, G. W; SNELL, S; SHERMAN, A. Administração de Recursos Humanos. São Paulo: Cengage Learning, 2003.

BOHLANDER, G. W; SNELL, S; SHERMANN, A. Administração de Recursos Humanos. São Paulo: Cengage, 2003.

BOOG, G. G; BOOG, M. T. Manual de Treinamento e Desenvolvimento: processos e operações. São Paulo: Pearson Prentice Hall, 2006.

BOOG, G. G; BOOG, M. T. Tempo de Convergir: o impactos nas pessoas, organizações e sociedade. São Paulo: Editora Gente, 2003. 
COSTA, C. A; BENTO, K. G. dos R; SÁ; F. B; ZIVIANE, F. Qualidade de Vida no trabalho, satisfação e motivação do trabalhador no setor do varejo. Revista da administração da UNIMEP. v. 11, n. 1, p 181-198, Janeiro/ Abril, 2013.

DAVENPORT, T. H; PRUSAK, L. Conhecimento empresarial: como as organizações gerenciam seu capital intelectual. Rio de Janeiro: Elsevier, 1998.

FIORELLI, J. O. Psicologia para Administradores. Integrando teoria e Prática. 5a ed. São Paulo: Atlas, 2006.

GOLEMAN, Daniel et al. Tecnologia e gestão da informação. Rio de Janeiro: Elsevier, 2009.

Hall, D. T. Careers in and out of organizations. London: Sage, 2002.

HAYNES, G. A. Testing the boundaries of choice overlod phenomenon: the effect of number of options an time pressure on decision difficulty and satisfaction.

Psychology \& Marketing, v. 26, n. 3, p 204212, 2009.

KRZNARIC, R; Como encontrar o trabalho da sua vida. Rio de Janeiro: Objetiva, 2012.

LACOMBE, F. J. M. Recursos Humanos: princípios e Tendências. 2. Ed. São Paulo: Saraiva, 2011.

LACOMBE, F. J. M; HEILBORN, Gilberto Luiz José. Administração: princípios e tendências. São Paulo: Saraiva, 2003.

MARRAS, J. P; Administração de recursos Humanos: do operacional ao estratégico. 14 ed. São Paulo: Saraiva, 2011.

MAXIMIANO, A. C. A. Introdução à administração. $6^{\mathrm{a}}$. ed. São Paulo: Atlas, 2004.

MYERS, D. G. Introdução à Psicologia

Geral. 5a. ed. Rio de Janeiro: LTC, 1999.
SCHWARTZ, B. O paradoxo da escolha: por que mais é menos. São Paulo: A Girafa, 2007.

SERVA, M; FERREIRA, J. L. O. O

fenômeno Workaholic na gestão de empresas. Rio de Janeiro. RAP. v. 40, n. 2, p 179-198, Mar./ Abr. 2004.

SOBRINHO, F. R; PORTO, J. B. Bem estar no trabalho: um estudo sobre suas relações com clima social, coping e variáveis demográficas. Curitiba. Revista de administração contemporânea. v. 16, n. 2, p. 253-270, Mar./Abr. 2012.

SOUZA, C. A Neoempresa. O Futuro da sua carreira no mundo em reconfiguração. São Paulo: Integrare Editora, 2012.

TANURE, B; NETO, A. C. ANDRADE, J. Executivos: sucesso e (in)felicidade. Rio de Janeiro: Elsevier, 2007.

THUROW, L. C. O futuro do capitalismo: como as forças econômicas de hoje moldam o mundo de amanhã. Rio de Janeiro. Rocco, 1997.

WENZEL, S. L. Gender, ethnic group, and homelessness as predictors of locus of control among job training participants. The Journal of Social Psychology, v.133, n.4, p. 495-505, 1993.

ZANELLI, J. C. BORGES-ANDRADE, J. E; BASTOS, A. V. B. (Org.). Psicologia, organizações e trabalho no Brasil. Porto Alegre: Artmed, 2004. 